\title{
LIN28B promotes growth and tumorigenesis of the intestinal epithelium via Let-7
}

\author{
Blair B. Madison, ${ }^{1,2,3}$ Qi Liu, ${ }^{4}$ Xue Zhong, ${ }^{4}$ Christopher M. Hahn, ${ }^{1,2,3}$ Nan Lin, ${ }^{1,3}$ \\ Matthew J. Emmett, ${ }^{1,3}$ Ben Z. Stanger, ${ }^{1,2,3,5,6}$ Ju-Seog Lee, $^{7,8}$ and Anil K. Rustgi ${ }^{1,2,3,9,10}$ \\ ${ }^{1}$ Division of Gastroenterology, University of Pennsylvania Perelman School of Medicine, Philadelphia, Pennsylvania 19104, \\ USA; ${ }^{2}$ Department of Medicine, University of Pennsylvania Perelman School of Medicine, Philadelphia, Pennsylvania 19104, \\ USA; ${ }^{3}$ Abramson Cancer Center, University of Pennsylvania Perelman School of Medicine, Philadelphia, Pennsylvania \\ 19104, USA; ${ }^{4}$ Center for Quantitative Sciences, Vanderbilt University School of Medicine, Nashville, Tennessee 37232, USA; \\ ${ }^{5}$ Abramson Family Cancer Research Institute, University of Pennsylvania Perelman School of Medicine, Philadelphia, \\ Pennsylvania 19104, USA; ${ }^{6}$ Department of Cell and Developmental Biology, University of Pennsylvania Perelman School of \\ Medicine, Philadelphia, Pennsylvania 19104, USA; ${ }^{7}$ Department of Systems Biology, The University of Texas MD Anderson \\ Cancer Center, Houston, Texas 77030, USA; ${ }^{8}$ Department of Biochemistry and Molecular Biology, Medical Research Center, \\ Biomedical Science Institute, School of Medicine, Kyung Hee University, Seoul 130-701, Korea; ${ }^{9}$ Department of Genetics, \\ University of Pennsylvania Perelman School of Medicine, Philadelphia, Pennsylvania 19104, USA
}

The RNA-binding proteins LIN28A and LIN28B have diverse functions in embryonic stem cells, cellular reprogramming, growth, and oncogenesis. Many of these effects occur via direct inhibition of Let-7 microRNAs (miRNAs), although Let-7-independent effects have been surmised. We report that intestine targeted expression of LIN28B causes intestinal hypertrophy, crypt expansion, and Paneth cell loss. Furthermore, LIN28B fosters intestinal polyp and adenocarcinoma formation. To examine potential Let-7-independent functions of LIN28B, we pursued ribonucleoprotein cross-linking, immunoprecipitation, and high-throughput sequencing (CLIP-seq) to identify direct RNA targets. This revealed that LIN28B bound a substantial number of mRNAs and modestly augmented protein levels of these target mRNAs in vivo. Conversely, Let-7 had a profound effect; modulation of Let-7 levels via deletion of the mirLet $7 c 2 / \operatorname{mirLet} 7 \mathrm{~b}$ genes recapitulated effects of Lin 28b overexpression. Furthermore, intestine-specific Let-7 expression could reverse hypertrophy and Paneth cell depletion caused by Lin $28 b$. This was independent of effects on insulin-PI3K-mTOR signaling. Our study reveals that Let-7 miRNAs are critical for repressing intestinal tissue growth and promoting Paneth cell differentiation. Let-7-dependent effects of LIN28B may supersede Let-7-independent effects on intestinal tissue growth. In summary, LIN28B can definitively act as an oncogene in the absence of canonical genetic alterations.

[Keywords: LIN28B; Let-7; intestinal epithelium; Paneth cells; colon cancer; CLIP-seq]

Supplemental material is available for this article.

Received June 24, 2013; revised version accepted September 10, 2013.

LIN28A and LIN28B specifically target Let-7 microRNAs (miRNAs) via binding to the terminal loop or pre-element (preE) region of pri-mRNAs and pre-miRNAs (Newman et al. 2008; Rybak et al. 2008; Viswanathan et al. 2008). LIN28A binds to the preE region of pre-Let-7 in the cytoplasm and recruits a terminal uridylase (TUTase), either Zcchc11 or Zcchc6, which adds an oligouridine tail to the 3' end of Let-7 (Heo et al. 2008, 2009; Hagan et al. 2009; Piskounova et al. 2011; Thornton et al. 2012). This blocks Dicer-mediated cleavage and leads to miRNA degradation. LIN28B binds to pri-Let-7 in the

${ }^{10}$ Corresponding author

E-mail anil2@mail.med.upenn.edu

Article is online at http://www.genesdev.org/cgi/doi/10.1101/gad.224659.113. nucleus and prevents Drosha-mediated cleavage and maturation via the microprocessor complex (Piskounova et al. 2011).

While the effects of LIN28B on the regulation of Let-7 miRNAs have been well documented, less is known about the action of LIN28 proteins on other RNAs. Studies have revealed that LIN28A and/or LIN28B bind to and promote the translation of certain mRNAs, such as IGF2, OCT4, CCNB1, CDK6, HIST1H2A, and BMP4 (Xu and Huang 
2009; Xu et al. 2009; Qiu et al. 2010; Ma et al. 2013). Recently, cross-linking, immunoprecipitation, and highthroughput sequencing (CLIP-seq) analysis of LIN28A in human embryonic stem (ES) cells revealed that LIN28A promotes the translation of RNA-binding proteins involved in splicing (Wilbert et al. 2012) but universally represses the translation of endoplasmic reticulum (ER)associated mRNAs (Cho et al. 2012). Additional roles for LIN28 proteins seem likely, since thousands of mRNA targets were identified in these studies (Wilbert et al. 2012; Cho et al. 2012; Hafner et al. 2013). An extensive analysis of LIN28B mRNA targets in primary tissue has not been pursued and would reveal potential insights into the biological properties of LIN28B.

LIN28 proteins appear to have important roles in controlling the growth and metabolism of normal and cancerous tissues. LIN28A or LIN28B expression is associated with chronic myelogenous leukemia (CML), hepatocellular carcinoma, neuroblastoma, and cancers of the lung, breast, ovary, cervix, colon, and rectum /Viswanathan et al. 2009; King et al. 2011a,b; Diskin et al. 2012; Molenaar et al. 2012). In addition, LIN28B expression is elevated or ectopically expressed in Wilm's tumors (Viswanathan et al. 2009), prostate cancer (Iliopoulos et al. 2009), and T-acute lymphoblastic leukemias (T-ALLs) (Rao et al. 2012). In cell lines, LIN28A or LIN28B are necessary and sufficient for promoting proliferation, soft agar colony formation, migration, invasion, and metastasis in xenograft mouse models (Iliopoulos et al. 2009; Viswanathan et al. 2009; King et al. 2011b). Consistent with these findings, Let-7 represses cell proliferation, the cancer stem cell phenotype, and metastasis (Johnson et al. 2007; Yu et al. 2007; Guo et al. 2013). While Let-7 repression is commonly viewed as a major mediator of LIN28B function, the mechanisms downstream from Let-7 do not always appear identical. For example, Src-mediated transformation of MCF10A cells requires LIN28Bmediated repression of Let-7, yet mRNA levels of the Let-7 target HMGA2 is unchanged (Iliopoulos et al. 2009), while in CML, colorectal cancer cell lines, C2C12 cells, or NIH3T3 cells, high LIN28A or LIN28B expression correlated significantly with high HMGA2 expression (Viswanathan et al. 2009; King et al. 2011b; Zhu et al. 2011). Thus, the actual relevance of specific Let-7 mRNA targets appears context-dependent and may vary potentially based on the affinity of the specific Let-7 miRNA isoforms with target mRNAs. In at least one context, repression of Let-7 promotes glucose metabolism, PI3K activation, and mTOR signaling via direct effects on IGF1, INSR, and IRS2 mRNAs (Zhu et al. 2011). The role of LIN28 proteins or Let-7 miRNAs in intestinal homeostasis and carcinogenesis is largely unknown.

We showed that $L I N 28 B$ expression in colorectal cancers is associated with poor prognosis and cancer recurrence and that LIN28B promotes migration, invasion, and metastasis of colorectal cancer cell lines in mouse xenograft models (King et al. 2011a,b). Considering these studies and the observation that LIN28B is more frequently up-regulated in a variety of other cancers (Viswanathan et al. 2009), we sought to elucidate the molecular mechanisms of LIN28B function in intestinal homeostasis and colorectal cancer. In transgenic mice expressing mouse Lin28b from the mouse Vil1 promoter (Vil-Lin28b mice), we observed significant intestine hypertrophy, crypt fission, and Paneth cell loss, which we show are Let-7-dependent. Transgenic mice also developed adenomas and adenocarcinomas in the small intestine and, to a lesser extent, the colon, providing genetic evidence that Lin $28 \mathrm{~b}$ can serve as an oncogene. Furthermore, unbiased and comprehensive analysis of LIN28B mRNA targets via ribonucleoprotein (RNP) CLIP-seq reveals that LIN28B boosts protein levels of individual targets, many of which are critical for cellular growth and epithelial identity. Therefore, the LIN28BLet-7 axis is critical for controlling proliferation in the crypt, while, conceivably, LIN28B may also directly promote a carcinogenesis program in a Let-7-independent manner.

\section{Results}

Reciprocal expression of Lin28b and Let-7 in the intestinal epithelium

We evaluated Lin28 a and Lin28b expression in wild-type mouse embryos and found that during development of the small intestine and colon, Lin28 a and Lin28b levels decline rapidly (Supplemental Fig. S1A,B). The expression pattern of Hmga2, a canonical Let-7 target, was highly similar to Lin28a and Lin28b. Mature Let-7 levels increase reciprocally during small intestine development, with a rapid increase between embryonic day 12.5 (E12.5) and E14.5 and between E16.5 and E18.5 (Supplemental Fig. S1C). Let-7 levels are nearly twofold higher in the colon, with Let-7b and Let-7c accounting for nearly half of total Let-7 levels (Supplemental Fig. S1D,E). Let-7 continues to rise postnatally in the small intestine (Supplemental Fig. S1F). Lin28b protein was detectable at all stages of development, mostly in endoderm, and localized to the nucleus (Supplemental Fig. S1G-J). Lin28b expression declined by E18.5 in small intestine and colon anlagen, with nuclear expression confined to the crypt compartments of the small intestine and colon at $3 \mathrm{wk}$ of age, particularly in the transit-amplifying region of crypts (Supplemental Fig. S1L,M). However, in differentiated intestinal epithelium, LIN28B was prominent in the cytoplasm (Supplemental Fig. S1N,O). In Caco-2 cells, LIN28B exhibited strong nuclear and faint cytoplasmic localization, with levels declining with differentiation (Supplemental Fig. S1P,Q).

Fractionation of crypt villus epithelia from jejunum of adult wild-type mice confirmed expression of Lin28b in the crypt, with lower expression in villus tip epithelia (Supplemental Fig. S1R). All nine mature Let-7 miRNAs were assayed as well; each miRNA was expressed at higher levels in villus tip epithelium, and thus total Let-7 levels were expressed at higher levels in villus tip epithelium (Supplemental Fig. S1R). Lin28a expression was not detected by RT-PCR in the adult intestinal epithelium (data not shown). Analysis of Lgr5-positive 
cells, which marks a population of intestinal epithelial stem cells (Sato et al. 2009; Barker and Clevers 2010), revealed that Lin $28 \mathrm{~b}$ is not expressed at significantly higher level in this population, consistent with immunohistochemistry (IHC) showing expression primarily in the upper region of the crypt (Supplemental Fig. S1S).

\section{Targeted expression of Lin28b in the intestinal epithelium causes mucosal hypertrophy}

Transgenic mice were generated to target high-level expression of Lin28b to the intestinal epithelium using the 13-kb mouse Vil1 promoter (Madison et al. 2002). Four lines of Vil-Lin28b mice were generated, with three exhibiting continuous expression at three different levels (low, medium, and high) and one line exhibiting variegated expression (Fig. 1A-F; data not shown). Mature Let-7 levels were repressed significantly in the epithelia of Vil-Lin28b mice (Fig. 1G,H). Hmga2 was coordinately upregulated by Lin $28 \mathrm{~b}$ expression (Fig. 1I). Of note, Lin $28 \mathrm{~b}$ overexpression had a minimal effect on Let-7c levels (Fig. 1G). Let-7c2 (on mouse chromosome 15) and Let-7a3 (at 22q13.31 in humans) share an atypical terminal loop, which lacks both the GRAG motif (recognized by the CCHC domain of LIN28B) and the GNGAY motif (recognized by the CSD domain of LIN28B) (Nam et al. 2011). Let- $7 \mathrm{~b}$, which is normally expressed at very high levels, is also moderately affected by LIN28B expression (Fig. 1G). Together, Let-7b and Let-7c account for nearly $80 \%$ of total remaining Let-7 levels in Vil-Lin28b transgenic mice.

Vil-Lin28b mice exhibited striking intestinal hypertrophy (Fig. 1J-L). The lack of sufficient numbers of aged Vil-Lin28b ${ }^{\mathrm{Hi}}$ mice precluded the quantification of intestinal hypertrophy in this line. Colon mass was greater in $\sim 50 \%$ of the transgenic mice examined. Animal weight was unchanged in all genotypes (data not shown). Crosssections of proximal small intestine from Vil-Lin28b mice revealed longitudinal folds/evaginations of the mucosa (Fig. 1M). Consistent with this, we observed an increase of intestinal mass per unit length in Vil-Lin28b mice (Fig. $1 \mathrm{~N}$ ) but no significant effect on small intestine length (data not shown).

\section{LIN28B binds to mRNAs and may promote their translation}

To determine whether any aspects of the Vil-Lin28b phenotype may be due to Let-7-independent effects of LIN28B, we queried RNA targets using a modified RNPCLIP-seq protocol using 254-nm UV light to cross-link RNA to RNA-binding proteins (Fig. 2A; Chi et al. 2009; Zhang and Darnell 2011). Samples were prepared from colonic epithelia of Vil-Lin28b ${ }^{\text {Med }}$ mice (two replicates), Caco-2 cells (three replicates), and DLD1 and Lovo cell lines (one replicate each) with a doxycycline-inducible LIN28B (Fig. 2B). Input RNA was isolated from ribosomal RNA (18s and 28s)-depleted total RNA. To identify sites
A

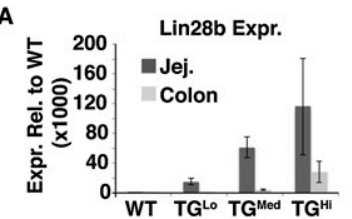

G
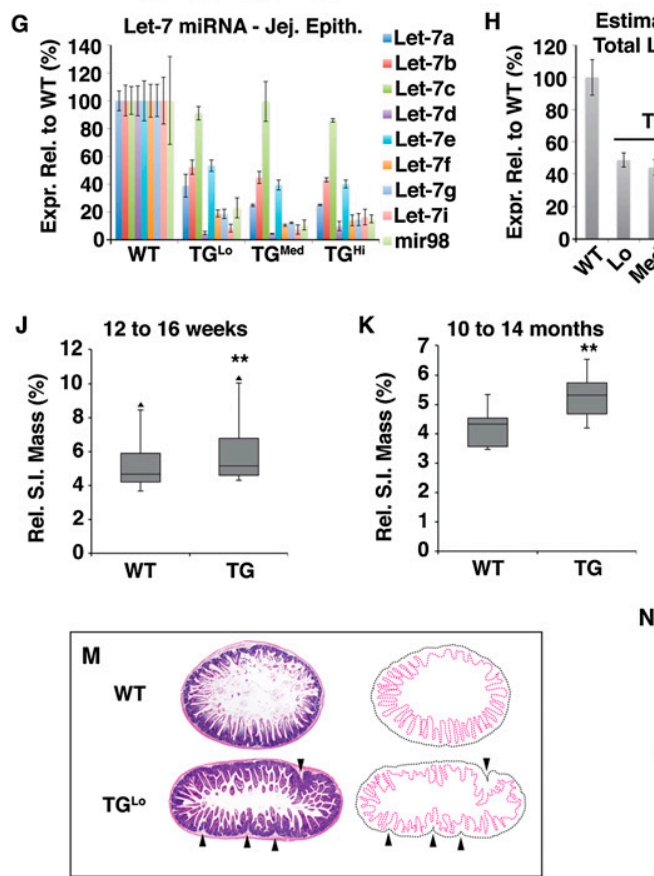

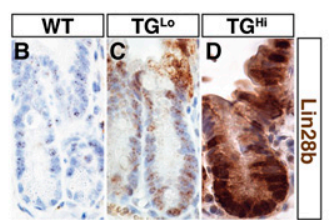

$\mathbf{H}$
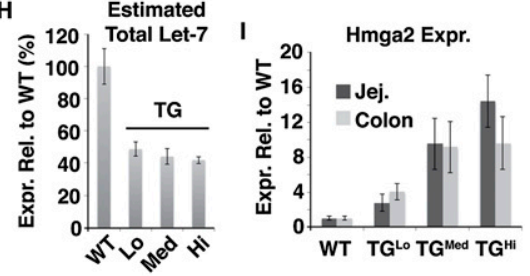

L

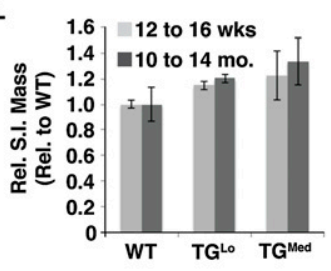

N

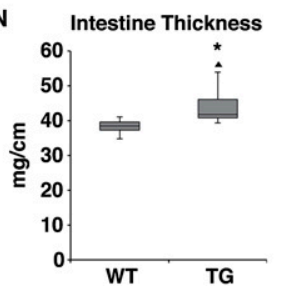

Figure 1. LIN28B drives mucosal hypertrophy in Vil-Lin28b mice. Vil-Lin28b mice generated using the 13-kb mouse Vil1 promoter exhibit low-, medium-, and high-level mRNA $(A)$ and protein $(B-D)$ expression. Immunofluorescence (IFC) of adult VilLin28b reveals nuclear expression in crypts $(E)$ but mostly cytoplasmic localization in villus epithelial cells of the jejunum $(F) .(G)$ Measurement of individual Let-7 levels reveals that Let-7 is significantly reduced, except for Let-7c. $(H)$ Estimated total levels compiled from $G$. $(I)$ mRNA levels of the Let-7 target Hmga2 is significantly elevated with increasing levels of Lin28b expression. $(J-L)$ Small intestine mass of adult wild-type (WT) and Vil-Lin28b (TG) mice. (M) Adult TG mouse small intestines exhibit increased longitudinal folds, where the mucosa has buckled inward (arrowheads); $4 \times$ magnification is shown. Outlines of intestine submucosa (black line) and epithelial layer (pink line) are shown to the right. (N) Intestine thickness (mass/unit length) of Vil-Lin28b (TG) mice. Magnification: $B-F, 400 \times ; M, 40 \times$. The mean is plotted $\pm \mathrm{SD}$ (bar graphs), where $n \geq 3 ;\left(^{\star}\right) P<0.05 ;\left(^{\star \star}\right) P<$ 0.01 , using a paired $t$-test (Student's) for littermates. Box plot whiskers represent $1.5 \times$ the interquartile range (IQR) above the third quartile or below the first quartile. The minimum and maximum outliers, when present, are represented by small triangles. 


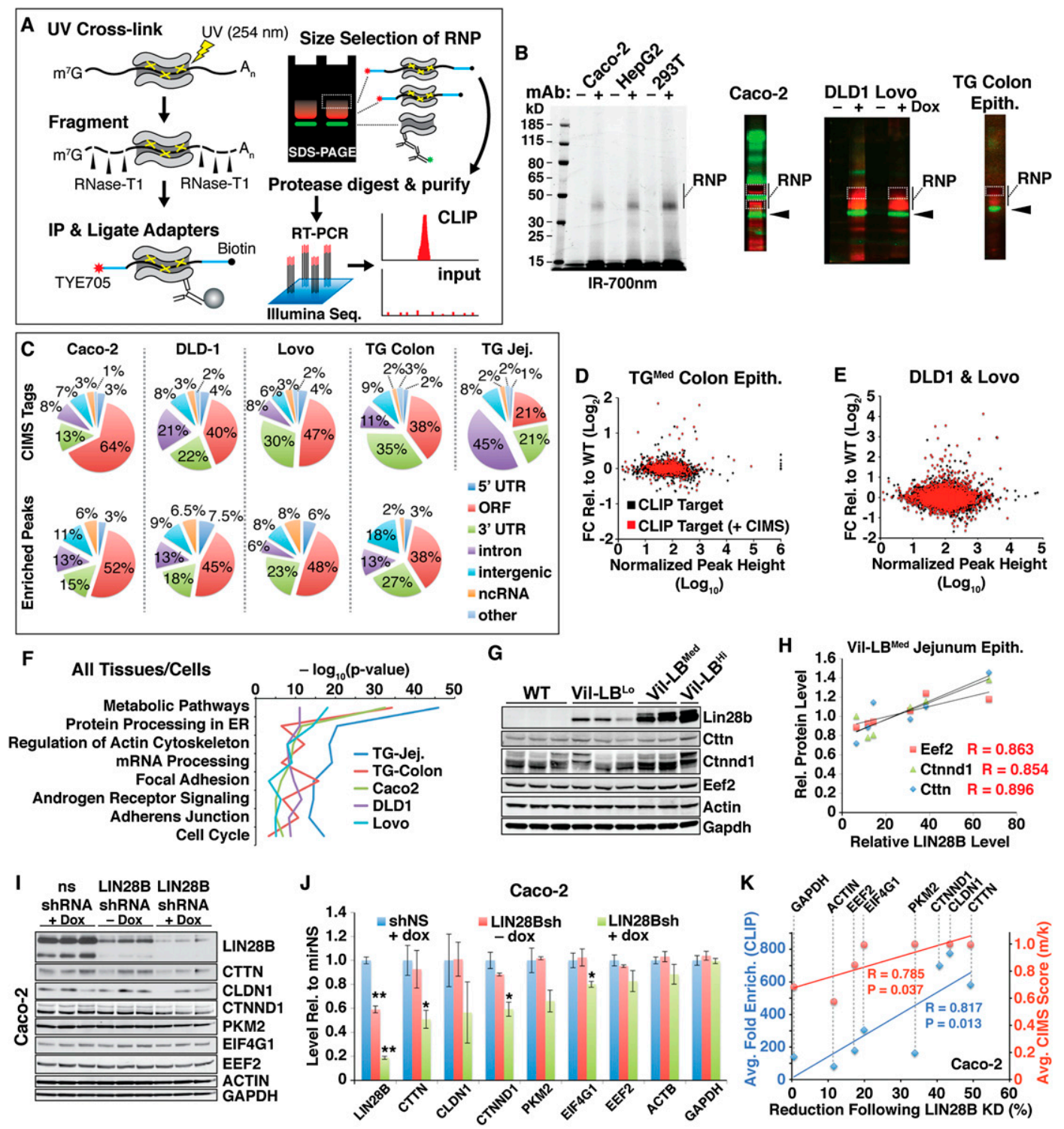

Figure 2. Identifying RNA targets of LIN28B. (A) Procedure for CLIP-seq for unbiased isolation of RNAs within LIN28B RNPs. Enrichment was determined relative to RNA sequencing (RNA-seq) from total RNA that was depleted of $28 \mathrm{~s}$ and $18 \mathrm{~s}$ rRNA. (B) CLIP of endogenous LIN28B in three cell lines using a rabbit monoclonal antibody followed by visualization by near-infrared (near-IR) fluorescence of TYE705-linked RNA adapters ligated to cross-linked RNPs. (B) For CLIP-seq, LIN28B-bound targets (in cross-linked RNPs) were excised following transfer to nitrocellulose (dotted box). Cross-linked RNPs were easily identified by near-IR fluorescence (red), while "empty LIN28B" (without cross-linked RNAs) (green) migrated just below these complexes. (B) Endogenous LIN28B was examined in Caco-2 cells, whereas exogenous LIN28B was examined in DLD1 and Lovo cells in Tet-inducible stable cell lines or colonic epithelium from Vil-Lin28 $b^{\text {Med }}$ mice. (C) Enriched peaks mapped largely to processed mRNAs primarily in the ORF or 3' UTR for all data sets. $(C)$ CIMSs also mapped largely to processed mRNAs. The "other" category includes reads that mapped upstream of or downstream from genes or at splice junctions. $(D, E)$ LIN28B does not affect steady-state levels of mRNA targets, as determined by microarray and CLIP-seq analysis (enriched transcripts [black]; enriched transcripts with CIMSs [red]) of Vil-Lin28b colonic epithelium $(D)$ and DLD1 and Lovo cells $(E)$ (DLD1 and Lovo microarrays from King et al. 2011a). (F) Kyoto Encyclopedia of Genes and Genomics (KEGG) (Ogata et al. 1999) and WikiPathway (Pico et al. 2008) categories enriched for CLIP-seq target sets identified from Vil-Lin28b jejunum crypts, Vil-Lin28b colon epithelium, and Caco-2, DLD1, and Lovo cells. Adjusted $P$-values were calculated using the Benjamini-Hochberg step-up procedure for multiple test adjustment. (G) LIN28B targets were examined by Western blot in lysates from Vil-Lin28b (low, medium, and high) jejunum epithelium. (H) CTTN, CTNND1, and EEF2 levels correlated with Lin28b levels, suggesting that Lin28b promotes the translation of these targets. (I) Six separate Caco-2 clones with an inducible shRNA against LIN28B or nonspecific (ns) shRNA were examined by Western blots for effects on target protein levels at low-level (-dox) and high-level (+dox) expression of the shRNA. (J) Quantification indicates that CTTN, CLDN1, CTNND1, PKM2, and EIF4G1 levels were reduced following LIN28B knockdown. $(K)$ In Caco-2 cells, sensitivity to LIN28B knockdown correlates with average fold enrichment (Supplemental Table S6) and the average CIMS score $(\mathrm{m} / \mathrm{k})$ of target mRNA. 
of intimate contact between RNA and protein, we exploited the phenomenon whereby UV cross-linking generates an irreversible adduct between an aromatic amino acid and the base of RNA or DNA (Zhang and Darnell 2011). RT frequently bypasses this covalently linked amino acid, resulting in a cross-link-induced mutation site (CIMS); these sites are almost exclusively deletions. We also performed CLIP-seq on isolated jejunum crypts from Vil-Lin $28 b^{H i}$ mice and focused exclusively on the CIMS signature (Fig. 2C). We observed that CLIP samples have 50-433 times as many sites with robust deletions compared with input (Supplemental Fig. S2A,B; Supplemental Table S2). Individual RNA targets are listed in Supplemental Tables S6-S10.

Enriched peaks were found mainly within mRNAs, with $70 \%-90 \%$ located within exonic sequences (Fig. $2 \mathrm{C})$, equally distributed throughout untranslated regions (UTRs) and coding regions. De novo motif analysis (MEME) (Bailey et al. 2006) of robust CIMSs from Caco2 cells yielded two motifs, one of which resembles the GGAG or GAAG consensus binding site found in the preE region of Let-7 pre-miRNAs (Supplemental Fig. $\mathrm{S} 2 \mathrm{C}$. We also found that GGAG was the most frequent tetranucleotide sequence found in enriched peaks in Caco-2 data, while other frequent tetranucleotides were purine-rich (data not shown). Since we observed lower replicability among less-abundant transcripts, indicating that these RNAs are more difficult to detect (Supplemental Fig. S2D,E), we focused on transcripts that possessed two criteria: at least one enriched peak and one robust CIMS with an average $\mathrm{m} / \mathrm{k}$ "score" $\geq 0.85$ in any one replicate. Neither the presence nor the score of a CIMS correlated significantly with transcript expression levels (Supplemental Fig. S2F,G; data not shown). Comparisons of enriched peaks with microarray data for DLD1 and Lovo and Vil-Lin28b colonic epithelia revealed that LIN28B does not significantly alter steady-state mRNA levels, which was true for enriched RNAs and those with CIMSs (Fig. 2D,E). Collectively, the CLIP-seq data indicate that LIN28B binds mRNAs and may modulate properties other than those associated with RNA stability and turnover.

Gene category and ontology analysis revealed that the "intracellular" cell component gene ontology (GO) category was the most significantly over-represented category for LIN28B targets among all cell types (Supplemental Table S3). LIN28B targets were enriched for regulators of metabolism, protein processing in the ER, the actin cytoskeleton, mRNA processing, and focal adhesion (Fig. 2F). Further scrutiny revealed that many LIN28B targets, among all tissues examined, are epithelial-specific (such as CTNND1) or associated with the translation machinery (such as EEF2 and EIF4G1) (Supplemental Tables S6-S10).

Immunoblots for cortactin (Cttn), p120-catenin (Ctnnd1), and Eef2 revealed that these targets are modestly elevated in the jejunum epithelium of Vil-Lin28b mice (Fig. 2G,H). There was no difference in protein levels of these targets or other targets (such as Cldn1, Pkm2, or Eif4g1) (data not shown) in Vil-Lin $28 b^{L o}$ mice compared with wild-type tissue, but target protein levels were increased with higher LIN28B expression for Cttn, Ctnnd1, and Eef2 (Fig. 2G,H). In Caco-2, knockdown of LIN28B caused a significant decrease of CTTN, CTNND1, and EIF4G1 levels, with a trend for depletion of CLDN1, PKM2, and EEF2 (Fig. 2I,J). We found that the average score of all CIMSs for a given mRNA is a significant predictor of functional impact; both fold enrichment and CIMS $\mathrm{m} / \mathrm{k}$ score correlated with LIN28B dependency (Fig. 2K). $\beta$-Actin and GAPDH were low-scoring targets (average CIMS $\mathrm{m} / \mathrm{k} \leq 0.5$ ) in Caco-2 cells, and their levels were unchanged (Fig. 2I,J). Cttn, Cldn1, Ctnnd1, Pkm2, Eif4g1, and Eef2 levels do not change with increasing depletion of Let-7 levels in the jejunum epithelium of $\operatorname{Let}^{I E C-K O}$, Vil-Lin28b ${ }^{L o}$, and Vil-Lin28b $b^{L o} /$ Let $^{I E C-K O}$ mice (data not shown), suggesting that these genes are not Let-7 targets. These results, along with our finding that LIN28B does not affect mRNA levels, suggest that LIN28B augments the translation of target mRNAs in vivo. This contrasts previous studies in HEK293 cells reporting that LIN28B modestly augments target mRNA levels but does not likely affect mRNA translation (Hafner et al. 2013).

Interestingly, LIN28B function in Caco-2 cells appears more robust than in the intestinal epithelium, since potent knockdown was required to see any effect on target protein levels in this cell line. Contrasting this, the effects on target protein levels were modest in VilLin28b mice and altogether absent in Vil-Lin28b ${ }^{L o}$ mice. Considering this, we postulated that Let-7 deficiency could be responsible for organ hypertrophy, which we next sought to elucidate in our mouse models.

\section{Let-7 represses intestinal epithelial growth and crypt proliferation}

Lin28b expression in the intestine appears insufficient to significantly deplete Let-7c and only modestly depletes Let-7b. Taken together, these miRNAs appear to be among the highest-expressed Let-7 miRNAs in the intestinal epithelium. To target these specific miRNAs, we generated a novel conditional allele for the bicistronic mirLet $7 c 2$ and mirLet $7 b$ miRNAs by homologous recombination in mouse ES cells (Fig. 3A,B), and an intestinal epithelial cell knockout (IEC-KO) was generated by crosses to Vil-Cre mice (Fig. 3C; Madison et al. 2002), referred to here as $L e t 7^{I E C-K O}$ mice. These mice exhibit severe depletion of Let- $7 \mathrm{~b}$ and Let-7c in the intestinal and colonic epithelia, resulting in a $40 \%$ depletion and $60 \%$ depletion of total Let-7 levels in the small intestine and colon, respectively (Fig. 3D-F). By targeting these specific miRNAs, we can coordinately deplete all Let-7 miRNAs via crosses with Vil-Lin28b transgenic mice, which exhibit depletion of all other Let-7 miRNAs.

Let $7^{I E C-K O}$ mice exhibited very modest, but nonetheless significant, intestinal hypertrophy (Fig. 3G), whereas colon mass was unaffected (data not shown). The small intestine was also thicker (Fig. 3H,I). We suspected that increased mucosal growth occurred via increased rates of crypt fission, a process of gland division that occurs during intestinal growth (St Clair and Osborne 1985; Li et al. 1994). Quantification in $\operatorname{Let} 7^{I E C-K O}$ weanlings 

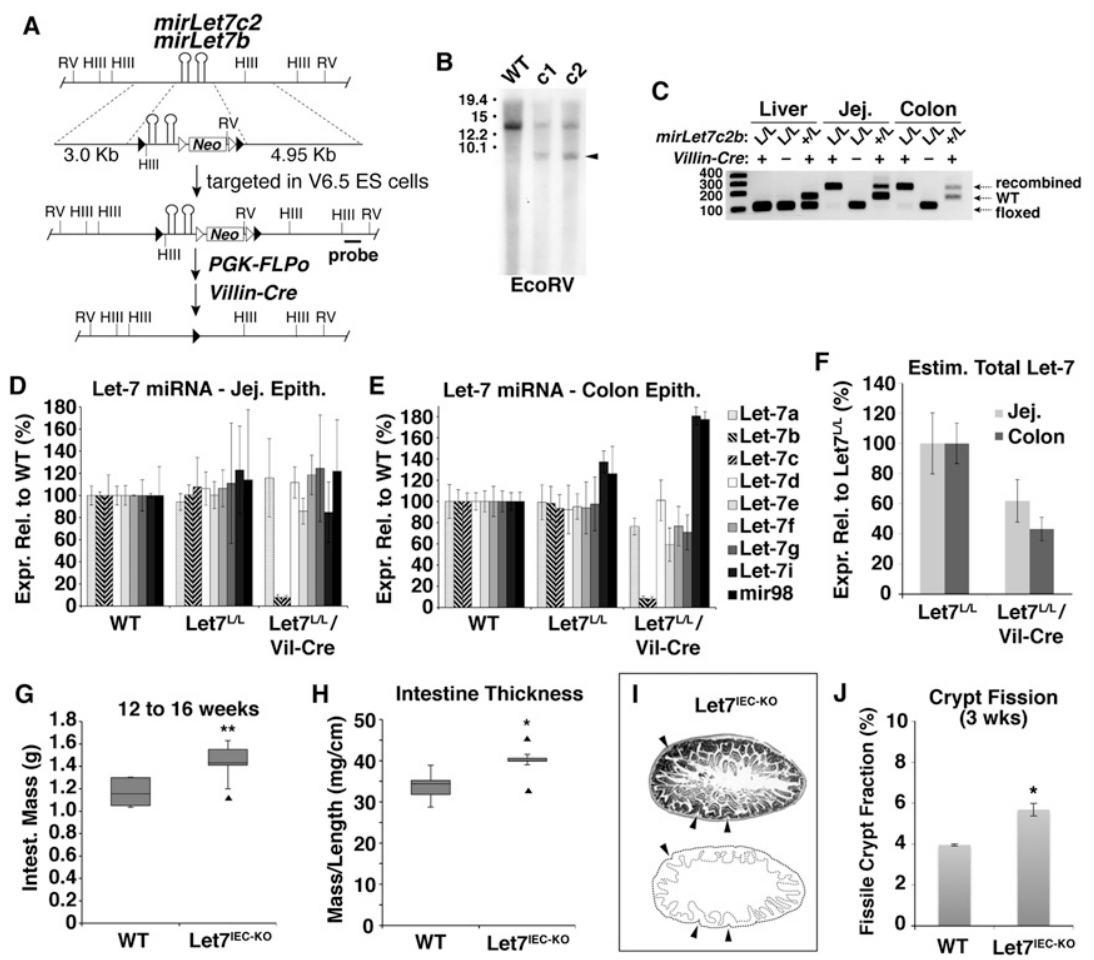

Figure 3. Let-7 controls growth of the small intestine. (A) Targeting strategy for generating a conditional (floxed) allele of mouse mirLet7c2 and mirLet7b. (B) Southern blots of two successfully targeted ES clones. $(C)$ PCR of genomic DNA confirms intestine-specific deletion of floxed (L/L) mirLet7c2 and mirLet $7 b$. Mature Let-7b and Let-7c levels are depleted $(>90 \%)$ in intestine-specific knockouts using Vil-Cre in jejunum $(D)$ and colon $(E)$ epithelium. $(F)$ Compilation of data from $D$ and $E$ reveals that deletion of mirLet $7 c 2$ and mirLet $7 b$ yields an estimated $\sim 40 \%$ and $\sim 60 \%$ reduction of total Let- 7 levels in the jejunum and colon, respectively. Depletion of Let-7b and Let-7c causes intestinal hypertrophy $(G)$, with a significant increase of intestine thickness at 12-16 wk of age $(H)$. (I) H\&Estained sections of adult small intestine reveal folds/evaginations similar to those seen in VilLin28b mice. (J) Rates of crypt fission are increased in Let- $7^{\mathrm{IEC}-\mathrm{KO}}$ mice. Magnification: $I, 40 \times$. For bar graphs, mean is plotted $\pm S D$, where $n \geq 3$. revealed an increased fraction of fissile crypts (Fig. 1J). This partial recapitulation of the Vil-Lin28b phenotype indicated that Let-7 controls intestinal growth. An increased rate of crypt fission is likely responsible for intestinal hypertrophy.

\section{Let-7 is required for Paneth cell differentiation}

Intestinal hypertrophy may compromise the program of epithelial differentiation, so we examined epithelial cell lineage identity. Paneth cell numbers appeared reduced with increasing Lin $28 \mathrm{~b}$ expression and were severely depleted in Vil-Lin28b ${ }^{H i}$ mice (Fig. 4B; Supplemental Fig. S3D). Cleaved caspase-3 IHC did not reveal an increase of apoptosis within crypts or at the bases of crypts (data not shown), suggesting that Paneth cells are not depleted by cell death. Goblet cells only appeared affected in Vil-Lin28 $b^{\mathrm{Hi}}$ mice, with numbers depleted in some regions of both the small intestine (Supplemental Fig. S3H) and colon (data not shown). Neither enteroendocrine nor enterocyte lineages were affected in VilLin28b mice (Supplemental Fig. S3I-P). Paneth cells were modestly affected in adult $L e t 7^{I E C-K O}$ mice, with a slight decrease of Paneth cell markers (Fig. 4G; data not shown). Coordinate depletion of Let-7 levels in compound VilLin $28 b^{L o} /$ Let $7^{I E C-K O}$ mice caused a significant reduction of Paneth cells (Fig. 4E,G). To examine Let-7 dependency of this phenotype, intestine-specific expression of Let-7a with a doxycycline-inducible transgene (iiLet7 mice) was pursued that yields a variegated expression pattern (Fig. 4H). Let-7a levels in GFP-sorted crypt epithelium from Vil-Lin28b $b^{\text {Med }} /$ iiLet 7 mice were restored to wild-type levels or increased approximately threefold in GFP-sorted crypts from iiLet7 mice (Fig. 4I). Lysozyme expression was likewise restored to wild-type levels (Fig. 4J), while excess levels of Let-7a in GFP-sorted crypts from iiLet7 mice appeared to be detrimental to lysozyme expression and/or Paneth cell differentiation (Fig. 4J). Quantification of lysozyme-positive cells in GFP-negative and GFPpositive crypts confirmed the apparent rescue of this lineage (Fig. 4K-N), thus confirming the Let-7 dependency of Paneth cell differentiation.

\section{Lin28b promotes crypt proliferation and transformation via Let-7 repression}

Vil-Lin28 $b^{H i}$ mice had hyperplastic and expanded crypt regions in both adult (Fig. 5A-G) and weanling jejunum crypts (data not shown) of variable penetrance. VilLin28b $b^{\text {Med }}$ mice did not show this level of hyperplasia, but crypt proliferation frequently extended downward toward the bottoms of crypts, displacing the region where Paneth cells are normally located (Fig. 5D). We also observed a dose-dependent increase in apoptosis coincident with the increase in epithelial proliferation, as measured by immunostaining for cleaved caspase 3 (data not shown). The ability to promote both proliferation and apoptosis (or senescence) is a hallmark of oncogenes such as MYC or mutant KRAS (Evan et al. 1992; Brooks et al. 2001). This phenomenon indicates the presence of a signaling circuitry that provides negative feedback, perhaps to remove aberrant cells and prevent uncontrolled proliferation.

Considering the effects on proliferation and differentiation, we examined Vil-Lin28b transgenic mice for the development of intestinal polyps and cancer. At 3-10 mo 


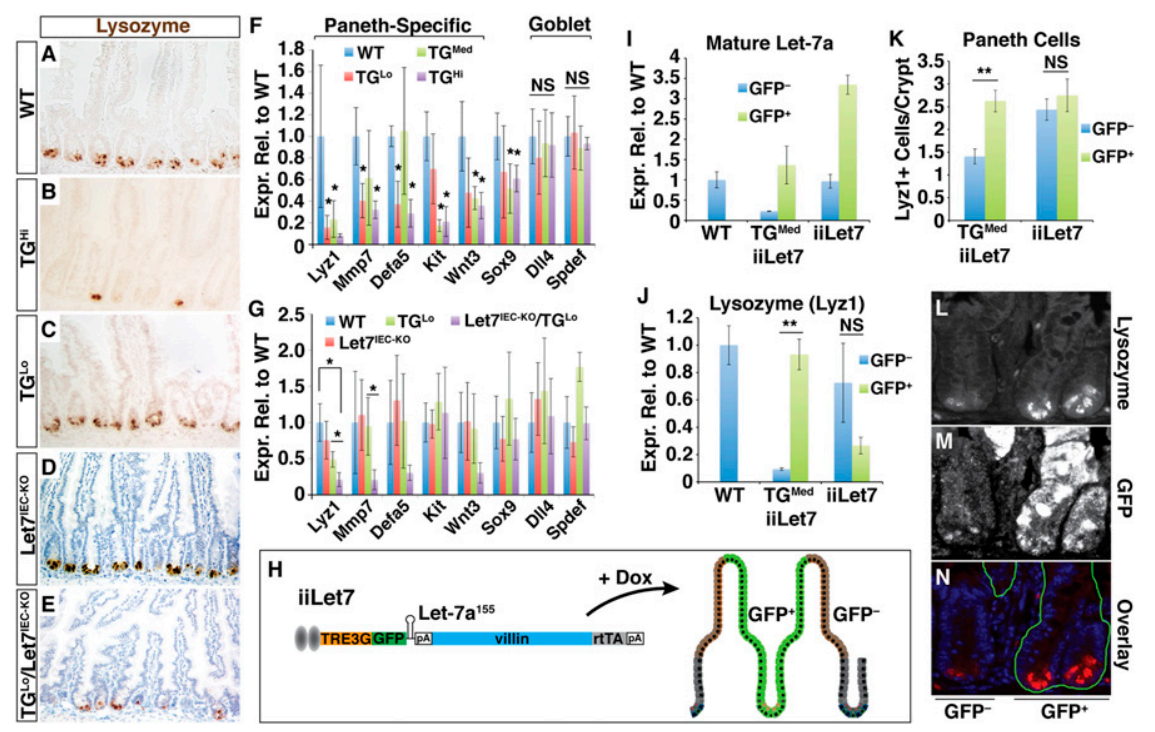

Figure 4. Let-7 is required for the Paneth cell lineage. $(A-D)$ IHC for lysozyme revealed a severe depletion of Paneth cells in the small intestine of Vil-Lin28 ${ }^{H i}$ (TGHi) mice (B) but not Vil-Lin28b ${ }^{L O}$ (TG-Lo) $(C)$ or Let $7^{I E C-K O}$ mice $(D)$. (E) Coordinated depletion of Let-7 in Vil-Lin28b ${ }^{\text {Lo }} /$ Let $7^{I E C-K O}$ mice causes severe depletion of Paneth cells. $(F)$ mRNA levels for Paneth cell lineage markers (Lyz1, Mmp7, Defa5, Kit, and $W n t 3)$ in jejunum epithelium are significantly decreased in all adult Vil-Lin28b mice, whereas Goblet markers (D114 and Spdef) were unaffected. Sox9, which is required for Paneth cell differentiation, is decreased in Vil-Lin28b $b^{\text {Med }}$ and VilLin2 $8 b^{H i}$ mice. $(G)$ Vil-Lin28b $b^{\text {Lo }} /$ Let $^{I E C-K O}$ mice have a significant depletion of lineage markers at $4.5 \mathrm{wk}$ of age. $(H)$ Schematic of a doxycycline-inducible transgene for intestine-specific expression of Let-7a (iiLet7 mice), which yields a variegated pattern of GFP expression. Crypt epithelium was sorted into GFP-negative and GFP-positive fractions for RT-PCR for Let-7a $(I)$ and lysozyme $($ Lyz1) (J). (K) Quantification of Paneth cell numbers in GFP-negative and GFP-positive crypts in Vil-Lin28b ${ }^{\text {Med }} /$ iiLet7 mice and iiLet7 mice. (L-N) Rescue of Paneth cell lineage in Vil-Lin28b ${ }^{\text {Med }}$ /iiLet7 mice as revealed by IFC for GFP (green outline) and lysozyme (red). Magnification: $A-E$, $200 \times ; L-N, 400 \times$. Littermates were compared when possible, and the mean is plotted \pm SD (bar graphs), where $n \geq 3 ;\left({ }^{\star}\right) P<0.05 ;\left(^{\star \star}\right) P<$ 0.01 , using an unpaired $t$-test (Student's). For Paneth cell quantification, 25-30 crypts of each type $\left(\mathrm{GFP}^{-}\right.$or GFP ${ }^{+}$) of proximal small intestine from each mouse $(n \geq 3)$ were counted \pm S.E.M, where $P<0.01\left(^{\star \star}\right)$, using a paired $t$-test for $\mathrm{GFP}^{-}$and $\mathrm{GFP}^{+}$pairs of crypts.

of age, four of 30 transgenic mice developed adenomas (Supplemental Table S1). At 12-17 mo, we observed the development of adenomas or adenocarcinomas in the majority of Vil-Lin28b ${ }^{\text {Med }}$ and Vil-Lin28b ${ }^{\text {Hi }}$ mice (Supplemental Table S1). Lesions were typically polyp-shaped or flat and occasionally invasive adenocarcinomas (Fig. 5I-K). Adenomas and adenocarcinomas were restricted to the small intestine, except for the Vil-Lin28b ${ }^{H i}$ founder, which developed adenomas in both the small intestine and colon at $15.5 \mathrm{mo}$ (data not shown). Thus, these results provide direct evidence that Lin $28 \mathrm{~b}$ can function as an oncogene in the intestine and colon.

The relatively long latency of tumor incidence and the variability in size, severity, and multiplicity suggested that sporadic deregulation of other oncogenes or tumor suppressors may contribute to the carcinogenesis program in Vil-Lin28b mice. To assay Wnt signaling, which is frequently deregulated in colon cancer, we next microdissected paired adjacent normal tissues and polyp tissues from Vil-Lin28b mice for RT-PCR analysis. We assayed eight canonical Wnt (Tcf4/ $\beta$-catenin) target genes in six pairs of normal versus adenomatous tissues and found that most or all of these targets were up-regulated in adenomas (Fig. 5L). In addition, we examined $\beta$-catenin localization by immunofluorescence (IFC). While some adenomas displayed a membrane-bound pattern of $\beta$-catenin (Fig. $5 \mathrm{M})$, most adenomas and adenocarcinomas exhibited cytoplasmic or nuclear $\beta$-catenin (Fig. $5 \mathrm{~N}, \mathrm{O}$ ). By anti-HA IFC, we found that expression of exogenous Flag-HA-tagged Lin28b was frequently down-regulated in Vil-Lin28b mice, likely due to silencing of the mouse Villin promoter in adenoma and adenocarcinoma tissues (Fig. 5M-O). These data indicate that Wnt pathway activation occurs at a high frequency in polyps from Vil-Lin28b mice.

In vivo modulation of Let-7 levels was performed to determine the Let-7 dependency of the crypt hyperplasia phenotype. Neither Vil-Lin28b $b^{L O}$ nor Let $7^{I E C-K O}$ mice exhibited crypt hyperplasia by quantifying Ki67 expression and BrdU incorporation (Fig. 5G,P; data not shown), whereas Vil-Lin2 $28 b^{L O} /$ Let $7^{7 E C-K O}$ mice, which possess combined depletion of Let-7, exhibited increased BrdU incorporation (Fig. 5P) and expanded crypts (Fig. 5Q,R). Conversely, Let-7a restoration with the iiLet7 transgene completely reversed the hyperplasia in Vil-Lin28b $b^{\text {Med }}$ crypts (Fig. 5S-W). Interestingly, effects on BrdU incorporation were much greater than on Ki67 labeling (Fig. $5 \mathrm{~V}, \mathrm{~W})$, suggesting that Let-7 may specifically repress the G1-S transition of the cell cycle.

\section{Intestinal hypertrophy occurs without modulation of PI3K-Akt-mTOR signaling}

Previous reports have linked Let-7 to the regulation of the PI3K-Akt-mTOR signaling pathway (Zhu et al. 2011), and RNA expression analysis of epithelium from VilLin28b mice suggested that Lin28b may regulate genes involved in metabolism and caloric restriction (Supplemental Fig. S4A). However, we queried markers of mTOR signaling and the Let-7 targets Insr, Igf1r, Irs2, Kras, and Myc but found no alterations (Supplemental Fig. S4B,C). Further examination by microarrays revealed that LIN28B triggered increased mRNA levels of the Let-7 targets Hmga2, Igf2bp2, E2f5, Acvr1c, and Nr6a1 (Fig. 6D,E). We confirmed depletion of Let-7 miRNAs in isolated 

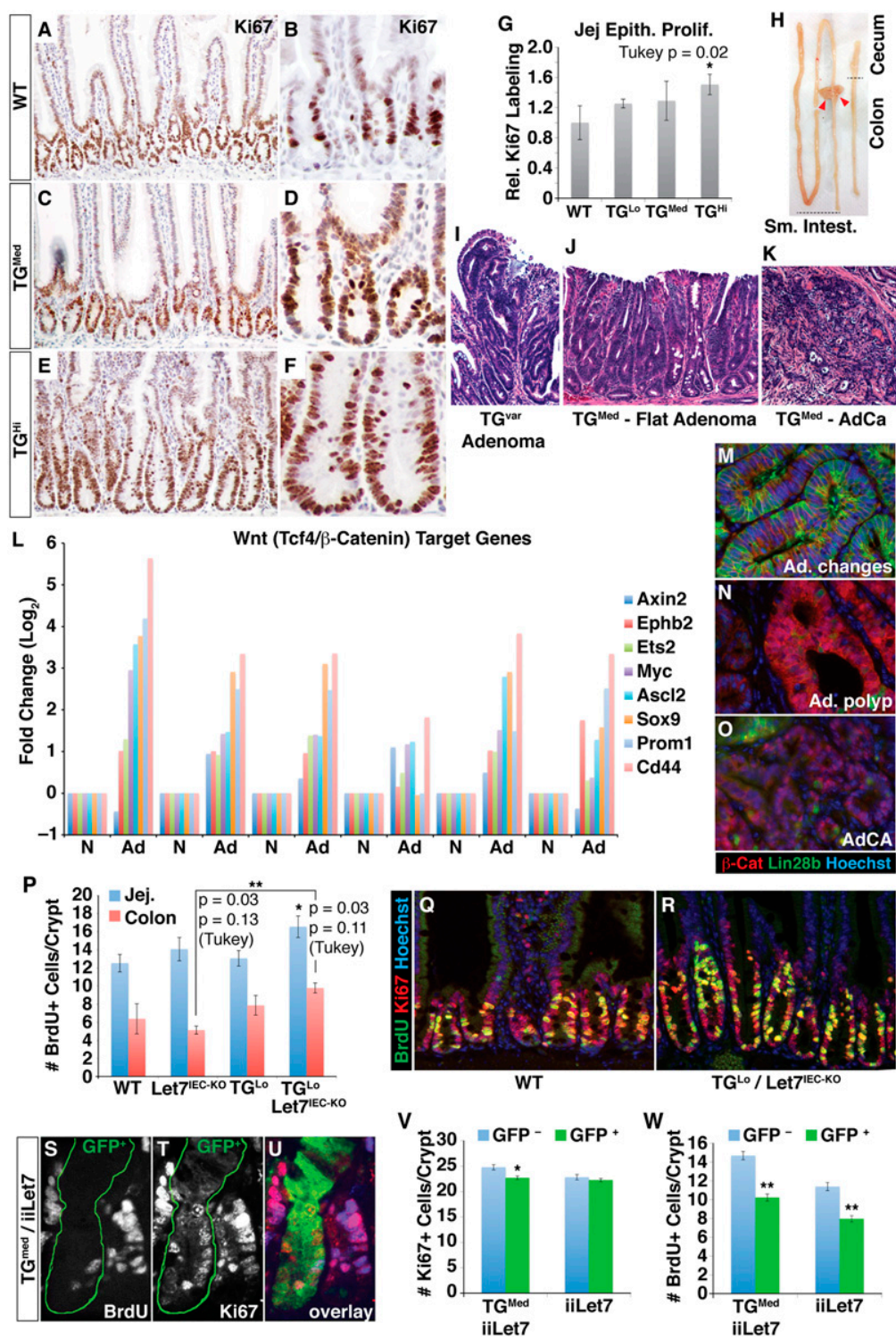

$\mathrm{TG}^{\mathrm{LO}} /$ Let7 $^{1 \mathrm{EC}-\mathrm{Ko}}$

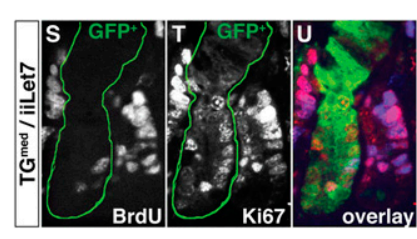

iiLet7

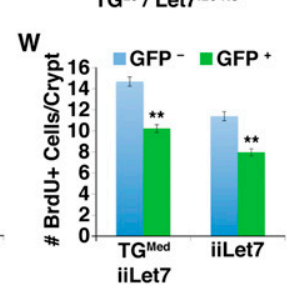

Figure 5. LIN28B drives epithelial hyperplasia and tumorigenesis. $(A-F)$ Vil-Lin28 mice exhibit crypt hyperplasia in the small intestine, as determined by Ki67 IHC. (G) Quantification of Ki67-positive cells indicates a significant increase in Vil-Lin28 $b^{H i}$ mice. $(H)$ Tumors/polyps (arrowheads) were found in Vil-Lin28b mice aged for 12-17 mo, almost exclusively in the small intestine. H\&E sections revealed the presence of adenomas $(I)$, flat adenomas $(J)$, and adenocarcinomas $(K)$. $(L)$ RT-PCR for Wnt target genes from eight microdissected adenomas (Ad) from the small intestines of four 15- to 17-moold Vil-Lin28b mice compared with normal (N) adjacent tissue. $(M-O)$ IFC for $\beta$-catenin and transgene-generated Lin $28 \mathrm{~b}$ (anti-HA) in adenomatous tissue and adenocarcinomas from Vil-Lin28b mice. $(P-W)$ Let-7 repression is responsible for crypt hyperplasia. $(P-R)$ Let $7^{I E C-K O} /$ Vil-Lin28b $b^{L o}$ mice exhibit a significant increase of BrdU incorporation in the small intestine compared with wild-type (WT) littermates (jejunum) or Let $7^{I E C-K O}$ mice (colon). $(S-W)$ Restoration of Let-7 levels in VilLin28b $b^{\text {Med }} /$ iiLet 7 mice represses crypt hyperplasia, as determined by Ki67 expression and BrdU incorporation. $(V, W)$ Quantification of Ki67-positive or BrdU-positive cells in GFP-negative and GFP-positive crypts in Vil-Lin28b $b^{\text {Med }} /$ iiLet7 mice and iiLet7 mice. For BrdU labeling, mice were injected with $\mathrm{BrdU}(100 \mathrm{mg} / \mathrm{kg}) 4 \mathrm{~h}$ prior to sacrifice. Magnification: $A, C, E, Q, R, 200 \times ; M, N, S-U, 400 \times ; I-K, 100 \times$. Littermates were compared when possible, and the mean is plotted $\pm \mathrm{SD}$ (bar graphs), where $n \geq 3 ;\left(^{\star}\right) P<$ $\left.0.05 ;{ }^{* \star}\right) P<0.01$, using Student's unpaired $t$-test. For Ki67 and BrdU quantification, 50-60 crypts $(G, P)$ or $25-30$ crypts of each type $\left(\mathrm{GFP}^{-}\right.$or $\left.\mathrm{GFP}^{+}\right)$ $(V, W)$ of proximal small intestines from each mouse were counted \pm S.E.M, where $P<0.01\left(^{\star \star}\right)$, using a paired $t$-test for $\mathrm{GFP}^{-}$and $\mathrm{GFP}^{+}$pairs of crypts. In $G$ and $H$, a mixed model ANOVA (nested ANOVA) was also performed with and without Tukey adjustment. crypts from Let $7^{I E C-K O}$ mice, Vil-Lin28b ${ }^{L o}$ mice, and VilLin28b $b^{L O} /$ Let $7^{I E C-K O}$ mice (Fig. 6C,D) and found that Let-7 target genes, including $\operatorname{Ig} f 2 b p 1$, were up-regulated in a Let-7-dependent manner in crypts from these mice (Fig. 6E-I). In GFP-sorted crypts from Vil-Lin $28 b^{\text {Med } / \text { iiLet7 }}$ mice, all Let-7 target mRNAs appeared to be repressed by exogenous Let-7a, with Hmga2 and Igf2bp 1 exhibiting the greatest change, although only Hmga2 changes were significant (Fig. 6J). Further analysis in wild-type crypts revealed that Hmga2, Acvr1c, and Igf2bp1 expression is mostly restricted to the crypt compartment, where it may regulate epithelial proliferation and/or differentiation of Paneth cells (Fig. 6K).

\section{Discussion}

Our model provides the first genetic in vivo evidence that LIN28B acts as an oncogene in intestinal and colon cancer whereby elevated LIN28B levels in the intestinal epithe- lium promote epithelial proliferation. In transgenic mice, we observed that higher LIN28B levels also correlate with increased incidence of adenocarcinoma. This is consistent with human epidemiological data illustrating that increased LIN28B levels are observed at early stages of colorectal cancer (King et al. 2011a; Piskounova et al. 2011), with high expression at both stages I and II disease correlating inversely with patient survival and higher probability of recurrence (King et al. 2011a).

We demonstrate that Let-7 normally represses intestinal mucosal epithelial growth through control of crypt fission and repression of cell cycle progression. We also show that Let-7 functions independently of PI3K-mTOR signaling to regulate growth. While PI3K-mTOR signaling appears to regulate animal size via effects in myoblasts and muscle tissue (Zhu et al. 2011), our data indicate that in the intestine, Let- 7 is critical for repression of Hmga2, Igf2bp1, Igf2bp2, E2f5, Acvr1c, and Nr6a1. In wild-type mouse crypts, we observed localiza- 
tion of LIN28B in the nucleus, where it likely sequesters Let-7 from the microprocessor machinery (Piskounova et al. 2011). Indeed, Let-7 levels are lowest in the crypt, and the known Let-7 target Hmga2 exhibits an expression pattern highly similar to endogenous LIN28B (expression in the upper crypt with diminishing levels toward villus tips). The Let-7 target Hmga2 alone is capable of driving proliferation (Lee and Dutta 2007) and has been reported to repress Ink4a/Arf (Cdkn2a) and potentiate E2F1 activity through the inhibition of $\mathrm{Rb}$ (Fedele et al. 2006; Nishino et al. 2008). In colorectal cancer, high Hmga2 expression correlates with metastasis and poor survival in patients (Wang et al. 2011). Hmga2 is responsible for the mouse pygmy phenotype, which occurs independently of growth hormone and insulin-like growth factor signaling and illustrates the critical effects of Hmga2 on growth (Zhou et al. 1995). Hmga2 is the most dramatically up-regulated Let- 7 target gene in the crypts of our animal models of Let-7 repression. In our rescue experi-
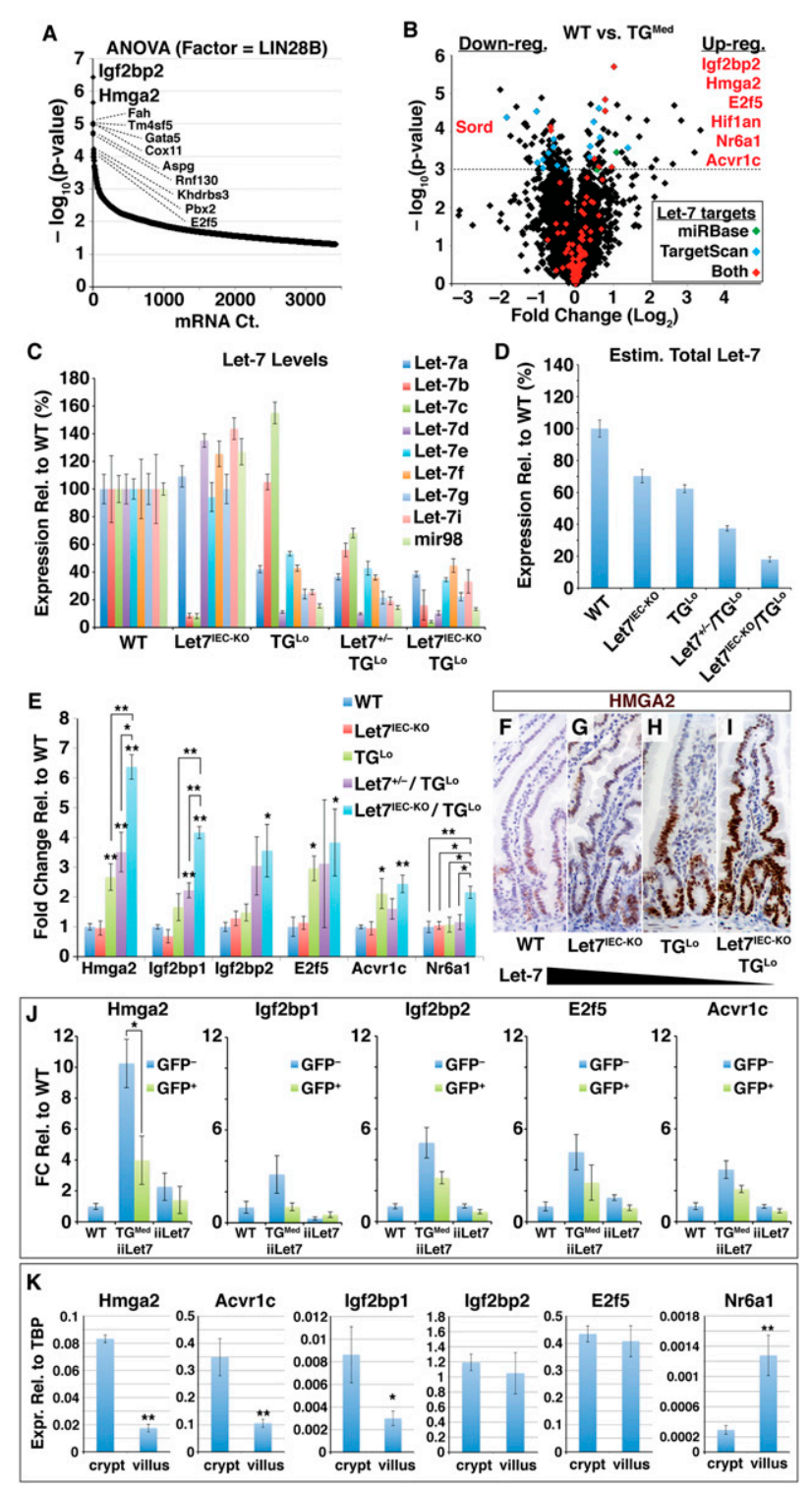

ments with the iiLet7 transgene, Hmga2 is also the most significantly repressed Let-7 target, perhaps suggesting that Hmga2 repression alone may rescue Paneth cell differentiation and crypt hyperplasia. Igf2bp1 and Igf2bp2 may also be important regulators of mucosal growth in the intestine, as this family of RNA-binding proteins is implicated in regulating proliferation and differentiation, among other processes (Bell et al. 2013; Hamilton et al. 2013).

Paneth cells, which secrete anti-microbial compounds, require a minimum amount of Let-7 for their proper differentiation, suggesting that Let-7 mRNA targets actively inhibit the differentiation of this lineage. We did not observe inflammation in unchallenged Vil-Lin28b mice, although they may possess alterations in their microbial flora and/or be susceptible following mucosal damage due to barrier loss, pathogen infection, or immune disorders. While Paneth cells have been reported to provide niche signals for $\mathrm{Lgr}^{+}$stem cells (Sato et al. 2011), we did not see any effects on this stem cell population in Vil-Lin28b mice (data not shown). This is consistent with an alternative hypothesis showing that Paneth cells are dispensable in vivo (Durand et al. 2012). Conversely, we saw increased proliferation throughout the crypt upon depletion of Let-7 in vivo, indicating that

Figure 6. Let-7 represses Hmga2, Igf2bp1, Igf2bp2, Hmga2, E2f5, and Acvr1c in intestinal epithelial crypts. $(A, B)$ Microarray analysis of adult jejunum and colon epithelium from Vil-Lin28 $b^{L o}$ and Vil-Lin $28 b^{\text {Med }}$ mice reveals up-regulation of known and predicted Let-7 target genes. (A) A three-way mixed model ANOVA $($ Factor $=$ LIN28B $)$ across all tissues and genotypes revealed that Igf2bp2 and Hmga2 are the most significantly changed mRNAs. $(B)$ Volcano plot using $P$-values (pairwise $t$-tests) relative to fold change of mRNA levels from jejunum epithelium of Vil-Lin $28 b^{\mathrm{Med}}$ mice. Predicted Let- 7 targets are indicated in green (miRBase predicted), blue (TargetScan predicted), or red (predicted by both algorithms), with Igf2bp2 and Hmga2 representing the most significantly changed mRNAs. Individual Let-7 miRNAs were assayed by RTPCR in crypts from wild-type (WT), Let ${ }^{I E C-K O}$, Vil-Lin28b ${ }^{L O}$, and Vil-Lin28 $b^{\text {Lo }} /$ Let $^{I E C-K O}$ mouse jejunum $(C)$, and total Let-7 values were estimated $(D)$. (E) RT-PCR confirmed that Hmga2, Igf2bp1, Igf2bp2, E2f5, Acvr1c, and Nr6a1 mRNAs increase with decreasing Let-7 dosage. $(F-I)$ IHC for Hmga2 shows increasing protein expression with decreasing dosage of Let-7 in $\operatorname{Let} 7^{I E C-K O}$, VilLin28b $b^{L o}$, and Vil-Lin28b $b^{\text {Lo }} /$ Let $7^{I E C-K O}$ mouse jejunum. (J) Restoration of mRNA levels of Let-7 targets Hmga2, Igf2bp1, Igf2bp2, E2f5, and Acvr1c in GFP-sorted crypts from iiLet7/ Vil-Lin28 $b^{\text {Med }}$ and iiLet7 mice. (K) RT-PCR for Let-7 targets in wild-type mouse intestine reveals that Hmga2, Acvr1c, and Igf2bp1 are expressed at higher levels in the jejunum crypt compartment, whereas Igf2bp2 and E2f5 are expressed in both villus and crypts, and Nr6a1 appears restricted to villus epithelium. Magnification: $F-I, 200 \times$. Box plot whiskers represent $1.5 \times$ the interquartile range (IQR) above the third quartile or below the first quartile. The minimum and maximum outliers, when present, are represented by small squares. Littermates were compared when possible, and the mean is plotted \pm SEM (bar graphs), where $n \geq 3 ;\left(^{\star}\right) P<0.01 ;\left(^{\star \star}\right) P<0.001$, using Student's unpaired $t$-test. 
Let-7 may supersede any detrimental effects on cellular proliferation caused by Paneth cell reduction. However, Paneth cells are not completely lost in any of our animal models of Let-7 inhibition, and the niche factor Wnt3 is only partially depleted.

In our previous studies, we showed that LIN28B promoted metastasis of colon cancer in xenograft tumor models (King et al. 2011a). However, we also observed that LIN28B-overexpressing cell lines generated primary tumors that appeared more glandular and differentiated (possessing epithelial morphology) compared with empty vector cell lines (King et al. 2011a). This also appears consistent with other studies in which LIN28B-expressing adenocarcinomas appear more glandular, whereas LIN28A-expressing tumors appear poorly differentiated (Piskounova et al. 2011). Thus, although Let-7 repression is a common theme, the effects on tissue differentiation are likely divergent for LIN28A and LIN28B. Such a differential role may be reflected in our observation that LIN28A is not expressed in the adult intestine epithelium and is similarly absent from other adult tissues but is highly expressed in primordial germ cells and ES cells (West et al. 2009). Divergent or antagonistic functions of LIN28A and LIN28B could also explain why tumors frequently express either LIN28A or LIN28B but not both (Viswanathan et al. 2009; Piskounova et al. 2011). We observed that endogenous and exogenous LIN28B becomes localized to the cytoplasm in the differentiated intestinal epithelium and differentiating Caco-2 cells (data not shown), which may reflect contrasting roles in differentiated versus undifferentiated cells. In the cytoplasm, LIN28B may associate with polyribosomes and mediate effects on target mRNA translation upon differentiation.

Our study has revealed the oncogenic potential of LIN28B with a clear illumination of the importance of Let-7 miRNA dosage in controlling intestinal tissue growth and Paneth cell differentiation. The individual contribution of each Let-7 miRNA (and also each Let-7 gene) is less easily pinpointed. For example, Vil-Lin $28 b^{\text {Lo }}$ mice have modestly lower levels of mature Let- 7 than Let $7^{I E C-K O}$ mice, yet Let-7 target genes are significantly altered only in Vil-Lin28 $b^{L o}$ mice. The cumulative dosage of Let-7 in compound Vil-Lin28b $b^{L O} /$ Let $7^{I E C-K O}$ mice is likely much lower than that of Vil-Lin28 $b^{H i}$ mice, yet these mice expressing high levels of Lin28b appear to have more severe crypt hyperplasia. These discrepancies could be due to differences of potency of each Let-7 miRNA and/ or a nonlinear relationship between total Let-7 levels and target mRNAs. When we examined how each individual Let-7 miRNA correlates with the levels of each target mRNA, our estimated total level of Let-7 correlated most consistently with Let-7 targets (data not shown). Therefore, we propose a nonlinear relationship for Let-7 miRNAs and functional consequences in our model, in which Let-7 levels reduced to $\sim 60 \%$ of wild type in the intestinal crypt appear sufficient for Paneth cell differentiation and the control of epithelial proliferation.

The severe phenotype of Vil-Lin $28 b^{H i}$ mice also may be due to Let-7-independent functions of LIN28B or cooperation between Let-7-independent and Let-7-dependent functions. To this end, RNP CLIP-seq analysis may provide additional insights into differential properties of LIN28B, with our data showing that LIN28B targets proteins involved in metabolism, cell motility, translation/ ribosomes, protein processing in the ER, and epithelial integrity. A recent study revealed that LIN28A binds mRNAs that encode secreted and transmembrane proteins and specifically represses their translation in the ER /Cho et al. 2012). Conversely, we observed positive effects on protein translation as well as enrichment for the functional category "protein processing in the ER," which was observed in all cell types. Interestingly, ER-associated chaperone expression may be associated with normal epithelial differentiation in the intestine, where the transcription factor XBP1, a mediator of the unfolded protein response, is specifically expressed in transit-amplifying and post-mitotic epithelial cells (Schwitalla et al. 2013).

LIN28B binding alone may yield little effect, as we observed differences in functional efficiency of LIN28B on mRNA targets; robust LIN28B depletion in Caco-2 cells is required to see any effect on target protein levels, yet we saw no effect on targets by low-level expression in the intestinal epithelium in Vil-Lin28b mice. Secondary effectors or accessory proteins may be critical for augmenting effects on translation, and such factors may be elevated in aberrant or mutant cells. There may also be factors that enhance LIN28B RNP nuclear export and/or promote association with the translation machinery in the cytoplasm.

In our proposed model (Fig. 7), the role of LIN28B in the intestinal epithelium extends into multiple dynamic aspects of growth, differentiation, and tumorigenesis. At low levels, LIN28B is likely critical for homeostasis by promoting mucosal growth (via Let-7) and perhaps is also important for augmenting metabolism, translation, protein/ mRNA processing, and cell cycle control in a Let-7independent manner. Our study highlighted the critical relationship between LIN28B levels and Let-7 dosage, where, below a certain threshold, Let-7 depletion compromises Paneth cell differentiation and deregulates epithelial proliferation, causing an increased risk of carcinogenesis. At elevated levels, LIN28B exhibits properties of a critical oncogene by promoting cellular transformation in the intestinal epithelium.

\section{Materials and methods}

\section{Animal models}

Transgenic animals were produced by pronuclear injection of linearized DNA constructs into B6SJL F1 fertilized oocytes. Targeted modification and generation of a floxed allele of the mirLet7c2/mirLet $7 b$ locus was achieved in the V6.5 mouse ES cell line, and clones were karyotyped and then injected into Balbc blastocysts. For embryo studies, timed matings of CD-1 mice (Charles River Laboratories) were used. Induction of Let$7 \mathrm{a}^{155}$ from the iiLet 7 transgene was achieved by feeding doxycycline chow for $3 \mathrm{wk}$, starting at $3.5 \mathrm{wk}$ of age. Transgene construction and animal model characterization are detailed in the Supplemental Material and Figure 1. All animal studies were 


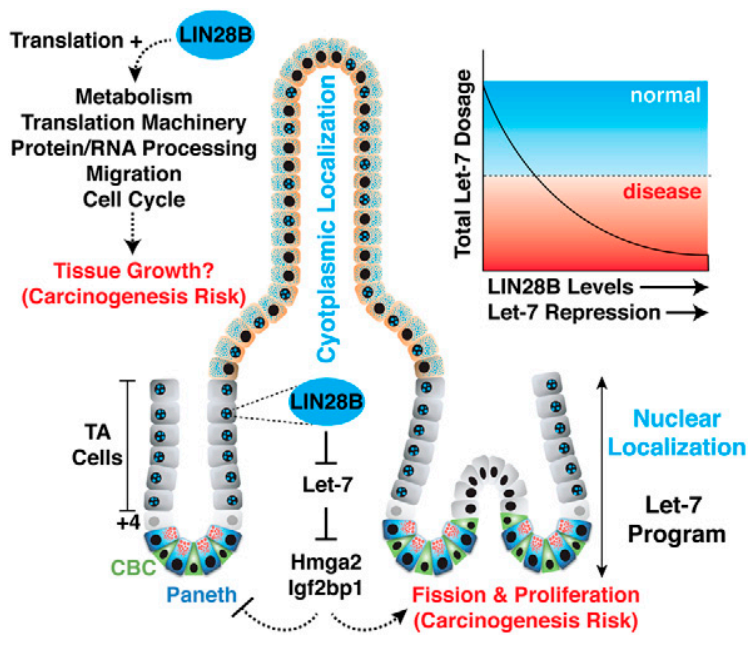

Figure 7. Model: LIN28B promotes intestinal growth via effects on Let-7 in the crypt. LIN28B is found exclusively in the nucleus of crypt epithelial cells. Here, Let-7 is critical for Paneth cell differentiation and the repression of crypt fission and proliferation, likely through repression of known Let-7 targets Hmga2 and Igf2bp1. In differentiated epithelium, LIN28B is found mostly in the cytoplasm. LIN28B may promote tissue growth via effects on mRNAs associated with metabolism, translation, and cell cycle. The effective dosage of Let-7 from a large reservoir of partially redundant miRNAs may help maintain Let-7 levels within a tolerable range, which prevents hyperplasia and supports Paneth cell differentiation. Depletion below a certain threshold fails to repress key Let-7 targets, yielding a "disease" state, such as hyperplasia or carcinogenesis. Transient depletion of Let-7 across this threshold, however, could be integral to normal processes, such as wound healing. Increased LIN28B levels drive carcinogenesis primarily through inhibition of Let-7, leading to deregulation of known oncogenes such as Igf2bp1 and Hmga2. Dotted lines represent proposed effects of LIN28B on mRNAs in these pathways.

approved by the University of Pennsylvania Institutional Animal Care and Use Committee.

Intestinal epithelium isolation, crypt villus fractionation, and polyp microdissection

Mouse intestine was cut lengthwise, rinsed in cold PBS, and then vortexed a few times in ice-cold calcium- and magnesium-free Hank's balanced salt solution (CMF-HBSS) containing $0.5 \mathrm{mM}$ DTT. Total intestinal or colonic epithelium was obtained by gentle shaking for $45 \mathrm{~min}$ in ice-cold CMF-HBSS containing $0.5 \mathrm{mM}$ DTT and $10 \mathrm{mM}$ EDTA, periodic vortexing for $30 \mathrm{sec}$ followed by an incubation for $30 \mathrm{sec}$ on ice, and repeating seven additional times. Epithelium was centrifuged at $300 \mathrm{~g}$ for $4 \mathrm{~min}$ at $4^{\circ} \mathrm{C}$, washed once with ice-cold CMF-HBSS, snap-frozen in a dry-ice ethanol bath, and stored at $-80^{\circ} \mathrm{C}$. Crypt villus epithelial fractionation for RT-PCR was carried out as described previously (Flint et al. 1991). For analysis of mTOR signaling by immunoblots, $\sim 5 \mathrm{~cm}$ of proximal jejunum was incubated in ice-cold CMF-HBSS containing $0.5 \mathrm{mM}$ DTT and $10 \mathrm{mM}$ EDTA on a rocking platform for $45 \mathrm{~min}$. Intestine epithelium was isolated as above, and crypts were then purified from this mixture by passing total epithelium over a $70-\mu \mathrm{m}$ cell strainer (BD Falcon, no. 352350). Retained epithelium contained the villus fraction, while flow-through contained crypts. Polyps were microdissected from small intestine under $10 \times-20 \times$ magnification on a dissecting microscope, and one-half was processed for histology, and one-half was snap-frozen in dry ice. Polyps were homogenized in Trizol, and total RNA was extracted for RT-PCR as described above.

\section{RNA isolation, RT-PCR, and microarray analysis}

Total RNA from cells was isolated with Trizol (Invitrogen) and used for RT reactions with oligo-dT primers using SuperScript III (Invitrogen). The TaqMan miRNA reverse transcriptase kit (Invitrogen) was used for Let-7 RT reactions. For microarrays, RNA was further purified using the RNeasy RNA purification kit (Qiagen) and submitted for hybridization to GeneChip Mouse Gene ST arrays (Affymetrix). Quantitative PCR used the Fast Sybr (Invitrogen) or TaqMan Fast Universal (Invitrogen) master mixes. Primers and probes are listed in Supplemental Table S5.

\section{RNP-CLIP-seq}

Adherent cell lines, colon epithelium, or jejunum crypts were washed once with ice-cold PBS and cross-linked with 254-nm UV radiation on ice. Cells were lysed and treated with DNaseI (Roche) and then Rnase-T1 (Fermentas). LIN28B RNPs were immunoprecipitated, washed, digested with Rnase-T1, ligated with RNA adapters, resolved on SDS-PAGE, and transferred to nitrocellulose. RNP complexes were excised and treated with proteinase-K (Roche), and RNA was purified and then amplified by RT-PCR. Single-read sequencing was carried out on an Illumina HiSeq 2000.

\section{Immunostaining and Western blots}

IHC and IFC were performed by antigen retrieval of deparaffinized and rehydrated mouse intestine sections in $10 \mathrm{mM}$ citrate buffer (pH 6.0). Anti-Lin28b IHC and anti-GFP IFC were achieved with the TSA Biotin system (Perkin Elmer). Western blots were performed with the Novex NuPAGE SDS-PAGE gel system (Invitrogen) in MOPS-SDS. Antibodies used for IHC, IFC, and Western blots are listed in the Supplemental Material and Supplemental Table S4.

\section{Acknowledgments}

Yu Shyr, Andres Klein-Szanto, Mary Ann Crissey, Arjun Jeganathan, Alfredo Penzo, Daniel Heitjan, and Jonathan Schug provided technical assistance. We appreciate the discussions with members of the Rustgi laboratory (Catrina King, Perry Mongroo, Maximilian Reichert, and Kathryn Hamilton). This work was supported by NIH R01-DK056645 (B.B.M., C.H., and A.K.R.), NIH K01DK093885 (B.B.M.), The Hansen Foundation (A.K.R.), National Colon Cancer Research Alliance (A.K.R.), NIH/NIDDK P30-DK050306 Center for Molecular Studies in Digestive and Liver Diseases, its Molecular Pathology and Imaging Facility, and its Molecular Biology/Gene Expression Facility. We are grateful to additional core facilities: University of Pennsylvania Next-Generation Sequencing, Transgenic and Chimeric Mouse, and Cell Culture; NIH/NIDDK (DK083355 and DK083111); the Pew Charitable Trusts; and the Abramson Family Cancer Research Institute. NCI P30 CA068485 and NCI P50 CA095103 provided additional support.

\section{References}

Bailey TL, Williams N, Misleh C, Li WW. 2006. MEME: Discovering and analyzing DNA and protein sequence motifs. Nucleic Acids Res 34: W369-W373. 
Barker N, Clevers H. 2010. Leucine-rich repeat-containing G-protein-coupled receptors as markers of adult stem cells. Gastroenterology 138: 1681-1696.

Bell JL, Wachter K, Muhleck B, Pazaitis N, Kohn M, Lederer M, Huttelmaier S. 2013. Insulin-like growth factor 2 mRNAbinding proteins (IGF2BPs): Post-transcriptional drivers of cancer progression? Cell Mol Life Sci 70: 2657-2675.

Brooks DG, James RM, Patek CE, Williamson J, Arends MJ. 2001. Mutant K-ras enhances apoptosis in embryonic stem cells in combination with DNA damage and is associated with increased levels of p19(ARF). Oncogene 20: 2144-2152.

Chi SW, Zang JB, Mele A, Darnell RB. 2009. Argonaute HITSCLIP decodes microRNA-mRNA interaction maps. Nature 460: 479-486.

Cho J, Chang H, Kwon SC, Kim B, Kim Y, Choe J, Ha M, Kim YK, Kim VN. 2012. LIN28A is a suppressor of ER-associated translation in embryonic stem cells. Cell 151: 765-777.

Diskin SJ, Capasso M, Schnepp RW, Cole KA, Attiyeh EF, Hou C, Diamond M, Carpenter EL, Winter C, Lee H, et al. 2012. Common variation at $6 \mathrm{q} 16$ within HACE1 and LIN28B influences susceptibility to neuroblastoma. Nat Genet 44: $1126-1130$.

Durand A, Donahue B, Peignon G, Letourneur F, Cagnard N, Slomianny C, Perret C, Shroyer NF, Romagnolo B. 2012. Functional intestinal stem cells after Paneth cell ablation induced by the loss of transcription factor Math1 (Atoh1). Proc Natl Acad Sci 109: 8965-8970.

Evan GI, Wyllie AH, Gilbert CS, Littlewood TD, Land H, Brooks M, Waters CM, Penn LZ, Hancock DC. 1992. Induction of apoptosis in fibroblasts by c-myc protein. Cell 69: 119-128.

Fedele M, Visone R, De Martino I, Troncone G, Palmieri D, Battista S, Ciarmiello A, Pallante P, Arra C, Melillo RM, et al. 2006. HMGA2 induces pituitary tumorigenesis by enhancing E2F1 activity. Cancer Cell 9: 459-471.

Flint N, Cove FL, Evans GS. 1991. A low-temperature method for the isolation of small-intestinal epithelium along the crypt-villus axis. Biochem I 280: 331-334.

Guo L, Chen C, Shi M, Wang F, Chen X, Diao D, Hu M, Yu M, Qian L, Guo N. 2013. Stat3-coordinated Lin-28-let-7HMGA2 and miR-200-ZEB1 circuits initiate and maintain oncostatin M-driven epithelial-mesenchymal transition. Oncogene doi: 10.1038/onc.2012.573.

Hafner M, Max KE, Bandaru P, Morozov P, Gerstberger S, Brown M, Molina H, Tuschl T. 2013. Identification of mRNAs bound and regulated by human LIN28 proteins and molecular requirements for RNA recognition. RNA 19: 613-626.

Hagan JP, Piskounova E, Gregory RI. 2009. Lin28 recruits the TUTase Zcchc11 to inhibit let-7 maturation in mouse embryonic stem cells. Nat Struct Mol Biol 16: 1021-1025.

Hamilton KE, Noubissi FK, Katti PS, Hahn CM, Davey SR, Lundsmith ET, Klein-Szanto AJ, Rhim AD, Spiegelman VS, Rustgi AK. 2013. IMP1 promotes tumor growth, dissemination and a tumor-initiating cell phenotype in colorectal cancer cell xenografts. Carcinogenesis doi: 10.1093/carcin/bgt217.

Heo I, Joo C, Cho J, Ha M, Han J, Kim VN. 2008. Lin28 mediates the terminal uridylation of let-7 precursor microRNA. Mol Cell 32: 276-284.

Heo I, Joo C, Kim YK, Ha M, Yoon MJ, Cho J, Yeom KH, Han J, Kim VN. 2009. TUT4 in concert with Lin28 suppresses microRNA biogenesis through pre-microRNA uridylation. Cell 138: 696-708.

Iliopoulos D, Hirsch HA, Struhl K. 2009. An epigenetic switch involving NF- $\mathrm{k}$, Lin28, Let-7 microRNA, and IL6 links inflammation to cell transformation. Cell 139: 693-706.

Johnson CD, Esquela-Kerscher A, Stefani G, Byrom M, Kelnar K, Ovcharenko D, Wilson M, Wang X, Shelton J, Shingara I, et al. 2007. The let-7 microRNA represses cell proliferation pathways in human cells. Cancer Res 67: 7713-7722.

King CE, Cuatrecasas M, Castells A, Sepulveda AR, Lee JS, Rustgi AK. 2011a. LIN28B promotes colon cancer progression and metastasis. Cancer Res 71: 4260-4268.

King CE, Wang L, Winograd R, Madison BB, Mongroo PS, Johnstone CN, Rustgi AK. 2011b. LIN28B fosters colon cancer migration, invasion and transformation through let7-dependent and -independent mechanisms. Oncogene 30: 4185-4193.

Lee YS, Dutta A. 2007. The tumor suppressor microRNA let-7 represses the HMGA2 oncogene. Genes Dev 21: 1025-1030.

Li YQ, Roberts SA, Paulus U, Loeffler M, Potten CS. 1994. The crypt cycle in mouse small intestinal epithelium. J Cell Sci 107: 3271-3279.

Ma W, Ma J, Xu J, Qiao C, Branscum A, Cardenas A, Baron AT, Schwartz P, Maihle NJ, Huang Y. 2013. Lin28 regulates BMP4 and functions with Oct4 to affect ovarian tumor microenvironment. Cell Cycle 12: 88-97.

Madison BB, Dunbar L, Qiao XT, Braunstein K, Braunstein E, Gumucio DL. 2002. Cis elements of the villin gene control expression in restricted domains of the vertical (crypt) and horizontal (duodenum, cecum) axes of the intestine. I Biol Chem 277: 33275-33283.

Molenaar JI, Domingo-Fernandez R, Ebus ME, Lindner S, Koster J, Drabek K, Mestdagh P, van Sluis P, Valentijn LJ, van Nes J, et al. 2012. LIN28B induces neuroblastoma and enhances MYCN levels via let-7 suppression. Nat Genet 44: 11991206.

Nam Y, Chen C, Gregory RI, Chou JJ, Sliz P. 2011. Molecular basis for interaction of let-7 microRNAs with Lin28. Cell 147: 1080-1091.

Newman MA, Thomson JM, Hammond SM. 2008. Lin-28 interaction with the Let-7 precursor loop mediates regulated microRNA processing. RNA 14: 1539-1549.

Nishino J, Kim I, Chada K, Morrison SJ. 2008. Hmga2 promotes neural stem cell self-renewal in young but not old mice by reducing p16Ink4a and p19Arf expression. Cell 135: 227-239.

Ogata H, Goto S, Sato K, Fujibuchi W, Bono H, Kanehisa M. 1999. KEGG: Kyoto encyclopedia of genes and genomes. Nucleic Acids Res 27: 29-34.

Pico AR, Kelder T, van Iersel MP, Hanspers K, Conklin BR, Evelo C. 2008. WikiPathways: Pathway editing for the people. PLOS Biol 6: e184.

Piskounova E, Polytarchou C, Thornton JE, LaPierre RJ, Pothoulakis C, Hagan JP, Iliopoulos D, Gregory RI. 2011. Lin28A and Lin28B inhibit let-7 microRNA biogenesis by distinct mechanisms. Cell 147: 1066-1079.

Qiu C, Ma Y, Wang J, Peng S, Huang Y. 2010. Lin28-mediated post-transcriptional regulation of Oct4 expression in human embryonic stem cells. Nucleic Acids Res 38: 1240-1248.

Rao S, Lee SY, Gutierrez A, Perrigoue J, Thapa RJ, Tu Z, Jeffers JR, Rhodes M, Anderson S, Oravecz T, et al. 2012. Inactivation of ribosomal protein L22 promotes transformation by induction of the stemness factor, Lin28B. Blood 120: 37643773.

Rybak A, Fuchs H, Smirnova L, Brandt C, Pohl EE, Nitsch R, Wulczyn FG. 2008. A feedback loop comprising lin-28 and let-7 controls pre-let-7 maturation during neural stem-cell commitment. Nat Cell Biol 10: 987-993.

Sato T, Vries RG, Snippert HI, van de Wetering M, Barker N, Stange DE, van Es JH, Abo A, Kujala P, Peters PJ, et al. 2009. Single Lgr5 stem cells build crypt-villus structures in vitro without a mesenchymal niche. Nature 459: 262-265.

Sato T, van Es JH, Snippert HJ, Stange DE, Vries RG, van den Born $M$, Barker N, Shroyer NF, van de Wetering $M$, Clevers 
H. 2011. Paneth cells constitute the niche for Lgr5 stem cells in intestinal crypts. Nature 469: 415-418.

Schwitalla S, Fingerle AA, Cammareri P, Nebelsiek T, Goktuna SI, Ziegler PK, Canli O, Heijmans J, Huels DI, Moreaux G, et al. 2013. Intestinal tumorigenesis initiated by dedifferentiation and acquisition of stem-cell-like properties. Cell 152: 25-38.

St Clair WH, Osborne JW. 1985. Crypt fission and crypt number in the small and large bowel of postnatal rats. Cell Tissue Kinet 18: 255-262.

Thornton JE, Chang HM, Piskounova E, Gregory RI. 2012. Lin28-mediated control of let-7 microRNA expression by alternative TUTases Zcchc11 (TUT4) and Zcchc6 (TUT7). RNA 18: 1875-1885.

Viswanathan SR, Daley GQ, Gregory RI. 2008. Selective blockade of microRNA processing by Lin28. Science 320: 97-100.

Viswanathan SR, Powers JT, Einhorn W, Hoshida Y, Ng TL, Toffanin S, O'Sullivan M, Lu J, Phillips LA, Lockhart VL, et al. 2009. Lin28 promotes transformation and is associated with advanced human malignancies. Nat Genet 41: 843-848.

Wang X, Liu X, Li AY, Chen L, Lai L, Lin HH, Hu S, Yao L, Peng J, Loera $S$ et al. 2011. Overexpression of HMGA2 promotes metastasis and impacts survival of colorectal cancers. Clin Can Res 17: 2570-2580.

West JA, Viswanathan SR, Yabuuchi A, Cunniff K, Takeuchi A, Park IH, Sero JE, Zhu H, Perez-Atayde A, Frazier AL, et al. 2009. A role for Lin28 in primordial germ-cell development and germ-cell malignancy. Nature 460: 909-913.

Wilbert ML, Huelga SC, Kapeli K, Stark TJ, Liang TY, Chen SX, Yan BY, Nathanson JL, Hutt KR, Lovci MT, et al. 2012. LIN28 binds messenger RNAs at GGAGA motifs and regulates splicing factor abundance. Mol Cell 48: 195-206.

Xu B, Huang Y. 2009. Histone H2a mRNA interacts with Lin28 and contains a Lin28-dependent posttranscriptional regulatory element. Nucleic Acids Res 37: 4256-4263.

Xu B, Zhang K, Huang Y. 2009. Lin28 modulates cell growth and associates with a subset of cell cycle regulator mRNAs in mouse embryonic stem cells. RNA 15: 357-361.

Yu F, Yao H, Zhu P, Zhang X, Pan Q, Gong C, Huang Y, Hu X, Su F, Lieberman J, et al. 2007. let-7 regulates self renewal and tumorigenicity of breast cancer cells. Cell 131: 1109-1123.

Zhang C, Darnell RB. 2011. Mapping in vivo protein-RNA interactions at single-nucleotide resolution from HITS-CLIP data. Nat Biotechnol 29: 607-614.

Zhou X, Benson KF, Ashar HR, Chada K. 1995. Mutation responsible for the mouse pygmy phenotype in the developmentally regulated factor HMGI-C. Nature 376: 771-774.

Zhu H, Shyh-Chang N, Segrè AV, Shinoda G, Shah SP, Einhorn WS, Takeuchi A, Engreitz JM, Hagan JP, Kharas MG, et al. 2011. The Lin28/let-7 axis regulates glucose metabolism. Cell 147: 81-94. 


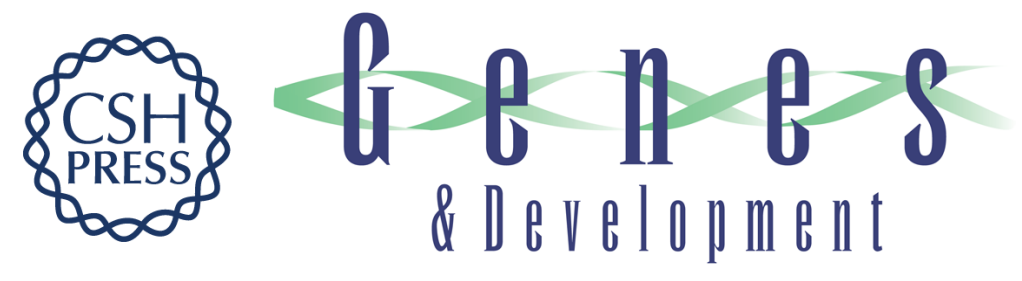

\section{LIN28B promotes growth and tumorigenesis of the intestinal epithelium via Let-7}

Blair B. Madison, Qi Liu, Xue Zhong, et al.

Genes Dev. 2013, 27:

Access the most recent version at doi:10.1101/gad.224659.113

\section{Supplemental http://genesdev.cshlp.org/content/suppl/2013/10/18/27.20.2233.DC1 Material}

References This article cites 49 articles, 14 of which can be accessed free at: http://genesdev.cshlp.org/content/27/20/2233.full.html\#ref-list-1

Creative This article is distributed exclusively by Cold Spring Harbor Laboratory Press for the first Commons six months after the full-issue publication date (see

License http://genesdev.cshlp.org/site/misc/terms.xhtml). After six months, it is available under a Creative Commons License (Attribution-NonCommercial 3.0 Unported), as described at http://creativecommons.org/licenses/by-nc/3.0/.

Email Alerting Receive free email alerts when new articles cite this article - sign up in the box at the top Service right corner of the article or click here.

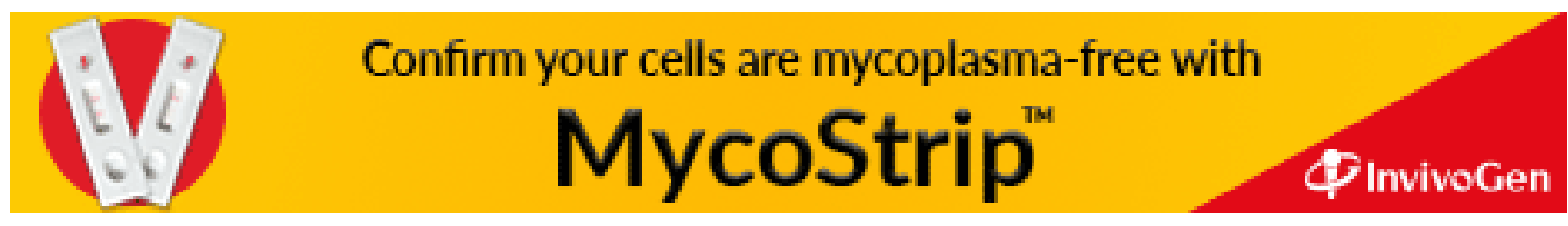

